\title{
A predominância de infrações ambientais contra a flora no sul de Minas Gerais de acordo com os dados da Polícia Militar
}

Este trabalho apresenta uma caracterização das autuações ambientais lavradas pelo 2o pelotão da 6a Companhia do Batalhão da Polícia Militar de Meio Ambiente do Estado de Minas Gerais entre os anos de 2015 e 2018, em dezenove cidades no sul do Estado. Trata-se de uma região abundante em recursos hídricos, com a incidência dos biomas de Mata Atlântica e Cerrado, onde são desenvolvidas atividades industriais, agropecuárias, minerárias, entre outras, ocorrendo um acentuado processo de urbanização. O objetivo principal é conhecer qual foi a classe de autuação que mais ocorreu no período de estudo na região, sendo que a pesquisa foi realizada através da análise de dados disponibilizados pela própria corporação, contendo informações sobre suas ações. Este estudo foi realizado visando disponibilizar informações que poderão ser utilizadas para a melhoria da gestão ambiental nessa região e em outras localidades. Em alguns estudos analisados foi verificado que as polícias ambientais são frequentemente destacadas para trabalhos das demais polícias não especializadas em determinada área de atuação. Analisando os dados sobre as autuações ambientais ocorridas na região observou-se uma maior ocorrência de infrações contra a flora e um alto volume de penalidades de multa, mostrando identidade com as pesquisas recuperadas. $O$ estudo ofereceu campo fértil a ser mais desenvolvido eis que, foram encontrados poucos trabalhos sobre autuações ambientais, penalidades aplicadas em razão de infrações ambientais e atuação da polícia de meio ambiente.

Palavras-chave: Polícia; Autuações Ambientais; Flora; Penalidades.

\section{The predominance of environmental violations against flora in the south of Minas Gerais according to Military Police data}

This work presents a characterization of the environmental sanctions drawn up by the 2nd Platoon of the 6th Military Environmental Police Company of the State of Minas Gerais between the years 2015 and 2018 in nineteen cities in the south of the state. This work presents a characterization of the environmental assessments drawn up by the 2nd platoon of the 6th Battalion Company of the Military Environment Police of the State of Minas Gerais between the years 2015 and 2018, in nineteen cities in the south of the state. The region is abundant in water resources and incidence of the Atlantic Forest and Cerrado biomes where industrial, agricultural and mining activities among others are developed with an accentuated urbanization process. The main objective is to find out which class of assessment mostly occurred during the study period in the region and the research was carried out through data analysis made available by the corporation itself, containing information about its actions. This study was carried out aiming to provide information which can be used to improve environmental management in this region and in other locations. It was found in some analyzed studies that environmental police are often assigned to work by other nonspecialized police in a given area of activity. Analyzing environmental sanctions data, that occurred in the region, there was a greater occurrence of infractions against flora and a high volume of fine penalties, showing identity to the recovered research. The study offered a fertile field to be further developed since there were few studies on environmental sanctions, penalties applied due to environmental infractions and the performance of the environmental police.

Keywords: Police; Environmental Sanctions; Flora; Penalties.

Topic: Planejamento, Gestão e Políticas Públicas Ambientais

Reviewed anonymously in the process of blind peer.

Luciano Ribeiro Rodrigues (iD)

Universidade Federal de Alfenas, Brasil

http://lattes.cnpq.br/0723630735882349

http://orcid.org/0000-0001-5720-1928

lucianorrodrigues@yahoo.com.br

Eduardo Gomes Salgado (iD

Universidade Federal de Alfenas, Brasil

http://lattes.cnpq.br/2363460036599181

http://orcid.org/0000-0002-8940-4014

eduardosalgado@unifal-mg.edu.br
Received: 26/04/2021

Approved: 27/05/2021
Referencing this:

RODRIGUES, L. R.; SALGADO, E. G.. A predominância de infrações ambientais contra a flora no sul de Minas Gerais de acordo com os dados da Polícia Militar. Revista Ibero Americana de Ciências Ambientais, v.12, n.5, p.681-697, 2021. DOI: http://doi.org/10.6008/CBPC2179-6858.2021.005.0053 


\section{INTRODUÇÃO}

A preocupação com as questões ambientais demandou pesquisas e conferências ao longo das últimas décadas, passando a integrar planos de governos, que muitas vezes dão à gestão ambiental grande destaque em suas políticas públicas, mostrando que o tema interessa a todos e merece atenção especial.

Cumpre esclarecer que muitos dos livros e estudos motivadores dessa realidade foram elaborados a partir da década de 1960 (CARSON, 1962; HARDIN, 1968) e início da década de 1970 (HARDIN, 1972), quando então a humanidade entendeu que a exploração em demasia poderia levar o meio ambiente a um colapso decorrente do exaurimento de todas as fontes naturais de matéria prima e elementos indispensáveis à manutenção da vida. Insta salientar a relevância do documento intitulado Limits to Growth, oriundo do estudo encomendado pelo Clube de Roma ao Instituto de Tecnologia de Massachusetts. Tal estudo, realizado utilizando a teoria dinâmica e desenvolvido através de um modelo computacional chamado "World3" analisou 12 cenários diferentes de padrões possíveis levando em conta dados relativos à população, produção alimentícia, industrial, poluição e os recursos naturais não renováveis, considerando o período entre 1900 e 2100 (MEADOWS et al., 1972).

Os cenários apresentados no estudo Limits to Growth mostraram como o crescimento populacional e os recursos naturais se interagiriam impondo limites ao crescimento industrial, vinculando a economia mundial ao meio ambiente e prevendo a ocorrência de um possível colapso no fim do século XX, ou durante o século XXI, caso recomendações não fossem adotadas (MEADOWS et al., 1972). O estudo tinha uma conotação de crítica à teoria do progresso, ou seja, condenava o crescimento econômico e por consequência o consumismo, pregando um sistema conhecido como Economia de Estado Estacionário, adotando um modelo de estagnação do crescimento da economia e da própria população mundial (MICHAM, 1995). Referida pesquisa foi amplamente divulgada, expandindo a discussão sobre a problemática ambiental e causando muita reflexão, ao passo em que alimentou o ceticismo e atraiu muitos pesquisadores.

Nesse contexto, novos paradigmas começaram a surgir em diferentes países e a proteção ambiental ganhou força, como nos Estados Unidos entre 1970 e 1976, com a promulgação de várias leis que exigiram a implantação de programas regulatórios, como a Lei do Ar Limpo, a Lei da Água Limpa, a Lei de Controle de Substâncias Tóxicas etc. Sendo assim estabelecida uma infraestrutura regulatória abrangente visando à proteção da coletividade em face de danos ambientais (PERCIVAL et al., 2013).

Na Alemanha foi implantado em 1971 o Programa de Meio Ambiente do Governo Federal, em 1972 foi promulgada a Lei dos Resíduos Sólidos, em 1974 a Lei Federal do Controle de Emissões e, posteriormente a promoção da revisão da Lei de Recursos Hídricos em 1976 através de novo diploma legal (WEDY, 2019).

No Brasil, no ano seguinte à realização da Conferência das Nações Unidas sobre o Meio Ambiente ocorrida em Estocolmo em 1972, foi criado o primeiro órgão ambiental voltado exclusivamente à questão ambiental, a SEMA - Secretaria Especial do Meio Ambiente (FERREIRA et al, 2017). Destacando, sobretudo, que o ápice da proteção ambiental brasileira culminou na edição do artigo 225 (Capítulo VI) da Constituição 
da República (BRASIL, 1988), exclusivamente, dedicado ao meio ambiente. Porém, antes da ganhar o espaço merecido na Carta Magna, a questão ambiental percorreu um longo caminho, sendo emblemático o estabelecimento da Política Nacional do Meio Ambiente - PNMA, através da Lei no 6.938/81 (BRASIL, 1981), quando foram criados os instrumentos de gestão ambiental como o licenciamento, a avaliação de impacto ambiental, dentre outros.

Os instrumentos criados na PNMA visam regular as atividades econômicas e antrópicas da sociedade moderna que porventura podem causar danos ambientais. Desse modo, para que sejam evitados os problemas ambientais já previstos em "The Limits to Growth" (1972), a fiscalização do uso dos recursos ambientais ganhou destaque através da criação de medidas de restrições e controle, bem como a regulamentação de penas em decorrência de transgressões. Os instrumentos de comando e controle dizem respeito a um conjunto de normas, procedimentos, regras e padrões que devem ser observados e cujo descumprimento pode gerar penalidades nas esferas administrativa, cível e criminal (LUSTOSA, 2003).

Conforme Motta et al. (1992) os instrumentos de comando e controle caracterizam-se pela adoção de meios de regulação direta através do estabelecimento de padrões de qualidade ambiental, controle do uso do solo, licenciamento, zoneamento, avaliação de impactos ambientais e penalidades, podendo ocorrer também regulação indireta como a imposição de rodízio de automóveis no âmbito municipal. Da mesma forma, os instrumentos de mercado podem representar formas de regulação direta e indireta, como a cobrança de taxas e tarifas (forma de regulação direta) ou pela cobrança de impostos e subsídios a equipamentos, insumos e produtos (forma de regulação indireta), segundo Varela (2001).

De acordo com a portaria № 14/2017 do Ministério do Meio Ambiente, o Instituto Brasileiro do Meio Ambiente e dos Recursos Naturais Renováveis (IBAMA) tem como uma de suas finalidades exercerem o poder de polícia ambiental no âmbito federal, competindo-lhe, dentre outras funções e ressalvadas as competências das demais entidades integrantes do Sistema Nacional do Meio Ambiente (SISNAMA), realizar a fiscalização e aplicação de penalidades administrativas ambientais ou compensatórias pelo não cumprimento das medidas necessárias à preservação ou correção da degradação ambiental, nos termos da legislação em vigor (MMA, 2017).

Leal et al. (2008) esclarecem que o poder de polícia decorrente da apuração dos crimes ambientais é exercido pela Polícia Judiciária da União e dos Estados por meio da Polícia Federal e da Polícia Civil das unidades da Federação, competindo-Ihes investigar, prevenir e reprimir tais delitos. Ainda, segundo os autores, as polícias de meio ambiente nos Estados e Distrito Federal dos quadros da Polícia Militar, além das delegacias especializadas, atuam no combate às infrações ambientais através da prevenção e repressão, sendo que a Polícia Militar Ambiental também exerce atividades de polícia administrativa aplicando penalidades aos infratores. Essa atribuição ou competência da Polícia Militar Ambiental decorre de leis estaduais, como também de convênios com órgãos ambientais nacionais ou locais e até mediante decisões administrativas do Poder Executivo estadual ou municipal.

No Estado brasileiro de Minas Gerais, o exercício do poder de polícia administrativa para fins de fiscalização, de aplicação de sanções administrativas, de cobrança e de arrecadação de tributos, multas e 
outras receitas é compartilhado entre a SEMAD, a FEAM, o IEF e o IGAM, admitida a sua delegação à Polícia Militar de Minas Gerais, de acordo com a Lei no 21.972/16, que dispõe sobre o Sistema Estadual de Meio Ambiente e Recursos Hídricos (MINAS GERAIS, 2016).

O aparato da Segurança Pública assim se destaca no combate às infrações ambientais no Brasil. Quanto ao exterior, cada país possui sua agência ambiental, sendo que os Estados Unidos e Canadá contam com policiais ambientais conhecidos como oficiais de conservação, que desempenham uma missão de grande relevância devido à indispensável proteção dos recursos naturais, embora suas atividades ainda tenham sido pouco estudadas (BLEVINS, 2013; LANHAM et al., 2014).

Portanto, criadas as leis e os instrumentos de política ambiental de cada país e especificamente em se tratando da fiscalização e autuação ambientais reconhecidas como ferramentas de comando e controle utilizadas em todo o mundo, se concretiza a gestão ambiental pública, sendo direcionado o presente estudo à atuação da polícia ambiental em uma área que cobre dezenove cidades do Sul do Estado de Minas Gerais em comparação a outros estudos realizados da mesma forma em outras localidades espalhadas pelo Brasil e pelo mundo. Trata-se de uma pesquisa inédita na região do 2 o Pelotão da 6a Companhia de Polícia de Meio Ambiente de Minas Gerais sediada na cidade de Varginha, que agrega um total de dezenove cidades e, para preencher esta lacuna, estudos já desenvolvidos na mesma unidade federativa, em outras localidades brasileiras e outros países, como os trabalhos apresentados por Vianna et al. (2019), Tavares et al. (2016) Rousseau (2009), e Lanham (2014), são norteadores.

As questões que norteiam este estudo são as seguintes: Quem realiza a fiscalização ambiental? Existe polícia de meio ambiente em outras localidades? As polícias ambientais trabalham somente com as questões dessa área específica? Existem classes diferentes de autuações ambientais e qual a que mais ocorre na região de estudo e em outros locais? Ocorreu aumento ou diminuição do número de autuações nas localidades e período pesquisados? Qual foi a penalidade mais aplicada no período de estudo? Houve um aumento ou diminuição do valor da soma total das multas aplicadas na região de estudo?

Esse estudo está estruturado do seguinte modo: a seção Introdução se refere a uma breve síntese da pesquisa que será realizada, na sequência tem a revisão literária com menção aos estudos recuperados, em seguida vêm as seções Métodos, Resultados e Discussão. Na seção relativa aos Resultados e Discussão, os dados fornecidos pelo 2o Pelotão da 6a Companhia de Polícia Militar de Meio Ambiente do Estado de Minas Gerais nas dezenove cidades do Sul de Minas são analisados considerando o número de autuações lavradas pela corporação, com a apresentação de gráficos que demonstram o comportamento dos números relativos às autuações, sendo realizada uma pequena comparação com os dados obtidos nos outros estudos, traçando ao final um paralelo com relação às condições de trabalho e demais peculiaridades entre as corporações relacionadas em toda a pesquisa. As últimas seções se referem às Considerações Finais onde serão lançadas as ponderações e sugestões para próximos estudos e as referências utilizadas na pesquisa. 


\section{REVISÃO TEÓRICA}

\section{Princípio do poluidor-pagador e o auto de infração ambiental}

Todos os ramos do Direito se fundamentam em princípios e, no caso do Direito Ambiental, um dos princípios de grande destaque se trata do princípio do poluidor-pagador, dispondo que pessoas físicas ou jurídicas são responsabilizadas, administrativa, civil e criminalmente, em decorrência de suas condutas e atividades consideradas lesivas ao meio ambiente (ARAGÃO, 2016). Através da aplicação do princípio do poluidor-pagador intenta-se evitar a degradação ambiental, pois os danos são coletivos enquanto o lucro é apenas do particular que degradou o meio ambiente (TRENNEPOHL, 2008).

Enfatizando as sanções administrativas, Costa (2010) destaca que o poder de polícia ambiental é materializado através do auto de infração, por meio da aplicação do art. 3o do Decreto no 6.514/2008 (BRASIL, 2008), impondo medidas como a advertência, a penalidade de multa, a apreensão de animais, produtos e subprodutos da flora, fauna e outros objetos da infração, instrumentos, petrechos, equipamentos ou veículos de qualquer natureza utilizados na ocorrência da infração, destruição ou inutilização de produtos e a suspensão de suas vendas e fabricação; suspensão parcial ou total das atividades; embargo parcial ou total de atividade ou obra e suas áreas correspondentes; demolição da obra e, restrição de direitos.

O Auto de Infração Ambiental é o documento onde se identifica o infrator, local de ocorrência, atividade desenvolvida, tipificação legal da conduta, penalidade, além de outras importantes e necessárias informações. Dessa forma, trata-se de um instrumento legal, de gestão territorial, no qual o agente público narra a ocorrência de um fato antijurídico e especifica as sanções incidentes àquele que praticou o ato, sendo assim materializado o princípio do poluidor-pagador, restando evidenciado o controle estatal e o comportamento da sociedade com relação ao cuidado ambiental em determinado local (ARAGÃO, et al 2016).

\section{Autuações ambientais}

Em recente estudo sobre os dados fornecidos pelo Ministério do Meio Ambiente acerca das infrações ambientais ocorridas entre 1998 e 2012 em nível municipal (5.564 municípios brasileiros), Peres, Uhr et al. (2016) constataram que a classe de infrações mais incidente (Tabela 1) e relevante quanto ao aspecto socioambiental se refere à flora, eis que pode afetar toda a biodiversidade, com efeitos deletérios sobre ecossistemas e nichos ecológicos.

Tabela 1: Infrações mais incidentes em algumas regiões e Estados do Brasil

\begin{tabular}{c|c|c}
\hline LOCALIDADES & PERÍODO & MAIORIA DAS INFRAÇÕES \\
\hline 1. Brasil & $1998 / 2012$ & Flora \\
2. Chapada Diamantina/BA & $2003 / 2018$ & Flora \\
3. Vale do Aço/MG & $2012 / 2017$ & Flora \\
4. Planalto Norte/SC & $2012 / 2014$ & Licenciamento/Condicionantes \\
5. Ceará & $2012 / 2015$ & Licenciamento/Condicionantes \\
6. Paraíba & 2014 & \\
\hline
\end{tabular}

Fontes: 1. Peres, UHR et al. (2016), 2. VIANA et al. (2019), 3. CAMPOS (2019), 4. BAZZANELLA et al. (2017), 5. ARAGÃO 
(2016), 6. TAVARES (2016).

Rousseau (2009) argumenta que o empreendedor que almeja maior rentabilidade se inclina a diminuir os gastos inerentes à regulamentação ambiental, infringindo as leis. Tal raciocínio traz à lembrança Beccaria (2002), quando ensinou que uma das principais hipóteses da teoria da dissuasão se refere ao fato dos infratores (criminosos) cometerem a infração (crime) quando os benefícios do ato superam os riscos, restando evidente o uso da razão (BARRET et al, 2018). Nesse contexto, Peres et al. (2016) explicam que o empresariado calcula o risco da não adequação aos padrões ambientais, ou seja, programa infringir a legislação entendendo obter maior vantagem mesmo que seja punido em decorrência da irregularidade.

Entretanto, é preciso cautela para cravar uma opinião a este respeito, já que de acordo com Rousseau (2009), se referindo às sanções monetárias, este é um tema e uma área de estudo que ainda está em construção, ou seja, a quantidade de pesquisas científicas sobre as multas impostas por infrações ambientais está aumentando e somente é possível a realização dessas pesquisas através do acesso aos dados e informações oriundos das instituições, o que muitas vezes não acontece em razão da própria inexistência de dados.

Uma pesquisa recente realizada no Estado de Michigan nos Estados Unidos levou em conta o argumento da EPA (Agência de Proteção Ambiental) que aduz que as penalidades de multa dissuadem os infratores a reincidirem, como também inibem novas infrações, comparando com os estudos existentes sobre a questão (BARRET et al., 2018). Contudo, de acordo com os autores do estudo as multas pecuniárias têm efeito no curto prazo, ou seja, a médio e longo prazo as corporações internalizam o custo da desconformidade.

Em um estudo realizado no Chile, foi possível notar que, muito embora a legislação estabeleça sanções como multas, a administração no exercício da tutela do meio ambiente pode ser flexível. Tal flexibilidade a depender de previsão legal, se traduz pela compensação ou reparação do dano, desde que o interesse coletivo não seja lesado, mostrando dessa forma uma evolução estratégica, posto não colocar a aplicação de multas como fator desencorajante de condutas lesivas (DELGADO, 2016).

Em pesquisa recente realizada na Amazônia Legal brasileira, foi verificado que os preços agrícolas influenciaram no desmatamento, isto é, o preço da soja e dos insumos agrícolas podem provocar o aumento ou a redução da taxa de desmatamento (FERREIRA et al., 2015). Assim, hodiernamente, além das penalidades aplicadas pelo Poder Público, o próprio mercado pode punir aquele que comete infrações ambientais, cumprindo destacar que foi observado nos Estados Unidos que o conhecimento dos consumidores acerca do cometimento de infrações ambientais pelas empresas gera impactos negativos, como a perda de mercado, já que a desconformidade ambiental afeta toda a coletividade (ROUSSEAU, 2009).

\section{Atuação da polícia ambiental}

Além da questão financeira retratada acima, muitos outros fatores podem contribuir para a variação do número de autuações ambientais, como a estruturação da fiscalização e mesmo a forma de 
atuação e atribuições da polícia ambiental. O presente estudo observou a atividade policial regulamentada na Política Nacional de Meio Ambiente, delineada pelo SISNAMA (Sistema Nacional de Meio Ambiente) e delegada pela União, Estados, Distrito Federal e em muitos Municípios. Trata-se de uma atividade que se desdobra em muitas ações e que apresenta inúmeros dados, mas que ainda é pouco pesquisada, ou seja, existem apenas alguns estudos gerando uma lacuna (LANHAM, 2014) que aos poucos vai sendo preenchida, fornecendo informações que certamente poderão ajudar a melhorar a gestão ambiental.

Nos Estados Unidos, as polícias de meio ambiente, conhecidas como agências policiais de conservação, historicamente surgiram entre o final do século XIX e início do século XX, sendo que no Estado de Michigan seu surgimento ocorreu no ano de 1887 e no Missouri em 1905 (FALCONE, 2004), e tem exercido a função especializada atinente à fiscalização e aplicação da legislação relativa à fauna aquática e proteção da vida selvagem no âmbito dos Estados e Governo Federal.

Naquele país, assim como no Brasil, há um modelo especializado de policiamento, regulamentado por lei, com a finalidade de proteger a vida selvagem e os recursos naturais, conforme explica Falcone (2004). Esclarece o pesquisador que os policiais ambientais são denominados guardas-florestais ou agentes de conservação e sua corporação é conhecida como polícia de recursos naturais e conservação, havendo este tipo de departamento tanto nos Estados como também no âmbito federal. O Órgão a nível nacional, EPA (Agência de Proteção Ambiental), mantém a Agência de Pesca e Vida Selvagem dos Estados Unidos, da mesma forma encarregada da responsabilidade de proteger a vida selvagem do país e seus recursos naturais através de seus agentes de gestão da vida selvagem, peixes e caça. No enquadramento estatal hodiernamente os agentes de conservação fazem parte dos Departamentos de Recursos Naturais (DNR) subdivididos nos Estados em vários departamentos menores, direcionados à fiscalização específica de parques estaduais, florestas, cursos de água, ocupação do solo e proteção ambiental de forma genérica.

De acordo com Falcone (2004) os agentes de conservação, ou policiais ambientais, acumularam funções não originárias de sua especialidade após a criação dos Departamentos de Recursos Naturais, decorrendo este fato da própria transformação da sociedade que nos Estados Unidos passou a ter mais acesso a atividades recreativas em diferentes frentes e também gozando de maior tempo de lazer. Assim, os policiais ambientais passaram a ter que adotar uma postura mais generalista não só protegendo o meio ambiente, como também prendendo suspeitos de crimes comuns, realizando buscas por pessoas desaparecidas, aplicando as leis de trânsito de veículos nos seus respectivos Estados. O resultado desse efeito reflete em agências policiais de conservação mais generalistas.

Um estudo baseado nos dados fornecidos pelo KDFWR (Departamento de Proteção à Vida Selvagem, Peixes e Navegação no Estado de Kentucky, Estados Unidos), englobando os anos de 2006 a 2011, em que ocorreram 42.366 infrações, com aumento de 2006 a 2008 e declínio entre 2009 e 2011, classificadas em violações à vida aquática, aos animais selvagens, à navegabilidade e violações gerais. As infrações ligadas ao meio ambiente foram maioria em comparação às violações gerais segundo Lanham (2014). Ressaltou o pesquisador que a partir de 2009 o sistema foi alterado com o direcionamento do foco nas questões ambientais, sendo aplicadas as leis gerais se exigida uma resposta imediata inexistindo outros 
policiais na ocorrência. Esta medida possibilitou aos policiais emitirem avisos educativos ao público sobre a importância da sua corporação e dos recursos naturais, evitando o cometimento de novas infrações, ponderando Lanham (2014) que a atividade educacional passou a fazer parte da rotina de forma integral e definitiva.

No Canadá, os oficiais da conservação realizam suas atividades ligadas ao meio ambiente que muitas vezes se restringem a aplicação da educação ambiental, se ocupando também de muitas atividades relacionadas a outros departamentos policiais. Lotados nas jurisdições municipais das cidades de Toronto, Calgary e Vancouver, é interessante pontuar que o trabalho dos oficiais de conservação é dirigido por denúncias de outros departamentos de polícia, realizando o patrulhamento ligado às ações humanas em parques que muitas vezes recebem acampamentos e manifestações sociais (LUSCOMBE et al. 2014). Esta característica revela um grande distanciamento entre as atividades desenvolvidas pela polícia de meio ambiente do Canadá e a ora pesquisada, que além de fiscalizar parques, também lida com atividades industriais, minerárias, dentre outras.

Importante destacar que, em Minas Gerais, a fiscalização ambiental e aplicação das sanções por infração às normas de proteção ambiental encontram-se disciplinadas nas leis estaduais de no 7.772/80 (Lei de Política de Proteção, Conservação e Melhoria do Meio Ambiente), lei no 13.199/99 (Política Estadual de Recursos Hídricos), lei no 14.181/02 (Política de Proteção à Fauna e à Flora Aquáticas e de Desenvolvimento da Pesca e da Aquicultura), lei no 20.922/13 (Política Florestal e de Proteção à Biodiversidade) e lei no 21.972/16 (Dispõe sobre o Sistema Estadual de Meio Ambiente e Recursos Hídricos).

A fiscalização, como também as infrações ambientais e penalizações, estavam dispostas no Decreto estadual no 44.844/08 que vigorou até março de 2018, quando entrou em vigor o Decreto estadual no 47.383/18. Portanto, o estudo engloba as fiscalizações e autuações ambientais ocorridas entre os anos de 2015 e 2018, durante a vigência dos dois dispositivos legais atinentes à Política Estadual de Meio Ambiente.

\section{METODOLOGIA}

Nesse estudo ocorreu análise de dados qualitativa (classes de autuações) e quantitativa (valores das multas aplicadas). Foram colhidos os dados relativos às ações do 2 Pelotão da 6a Companhia de Polícia Militar de Meio Ambiente do Estado de Minas Gerais, instalado na cidade de Varginha, fornecidos por meio dos relatórios em arquivo Excel correspondentes aos anos de 2015 a 2018. Assim, a pesquisa foi desenvolvida por meio da extração de dados resultantes do exercício do poder de polícia na aplicação de ferramentas de gestão ambiental. Portanto, este trabalho foi feito através da pesquisa em doutrinas, artigos científicos e legislação ambiental juntamente com a análise de dados fornecidos pelos agentes públicos.

O espaço de tempo pesquisado contempla os anos de 2015 a 2018, período que se refere ao início da coleta de dados praticada pela Polícia Ambiental da localidade, que ocorreu justamente a partir de 2015, abarcando os dados lançados até 2018. Os dados correspondem a fatos sociais devidamente documentados, ou seja, informações fornecidas pela polícia de meio ambiente que teoricamente 
retrataram a realidade da sociedade em determinado espaço e período de tempo, sendo que, segundo Olsen (2015), dados são informações desencarnadas e não o mesmo que conhecimento.

Assim, a presente pesquisa baseou-se em trabalhos já realizados sobre as autuações ambientais lavradas pelos policiais de meio ambiente em diversas localidades no Brasil (PERES et al., 2016, BAZZANELLA et al., 2017) e em outros países (LUSCOMBE et al., 2014), com realidades distintas, podendo assim mostrar as diferentes formas de se praticar a governança ambiental através da observação das peculiaridades e similitudes constatadas (DELGADO, 2016, BARRET et al., 2018).

O estudo se concentrou na área onde a segurança pública ambiental é realizada pelo 2 o Pelotão da 6a Companhia de Polícia Militar de Meio Ambiente do Estado de Minas Gerais, que abrande os seguintes municípios: Boa Esperança Cambuquira, Campanha, Carmo da Cachoeira, Conceição do Rio Verde, Coqueiral, Elói Mendes, Guapé, Ilicínia, Jesuânia, Lambari, Monsenhor Paulo, Olímpio Noronha, Santana da Vargem, São Bento Abade, São Thomé das Letras, Três Corações, Três Pontas e Varginha. Alguns desses municípios são banhados pelo Rio Verde e seus afluentes, além dos afluentes do Rio Sapucaí, sendo que esses importantes corpos hídricos deságuam na Represa de Furnas, que banha mais de trinta municípios, dentre eles Varginha, Guapé, Elói Mendes, Ilicínia, Boa Esperança e Três Pontas.

Referida localidade possui uma elevada heterogeneidade ambiental apresentando ecótonos da Mata Atlântica (IBGE, 2004) e Cerrado, ou seja, trata-se de uma região de transição entre os cerrados do Brasil Central e as Florestas Semidecíduas do Domínio Atlântico, conforme Oliveira-Filho et al. (citado por NAVES et al., 2012).

A região é cortada pela BR 381 e MG 491, além de outras importantes rodovias. O município mais populoso é Varginha, que dista cerca de $300 \mathrm{~km}$ da capital mineira Belo Horizonte, como também dos municípios paulistas de Campinas e São Paulo e em torno de $400 \mathrm{~km}$ da cidade do Rio de Janeiro, evidenciando uma localização estratégica do ponto de vista logístico. De acordo com o último levantamento censitário realizado (IBGE, 2010), a soma de habitantes cadastrados em todos esses dezenove municípios totalizou 454.390 e o espaço territorial em torno de $7.600 \mathrm{~km}^{2}$, ou seja, a área (território) somada dos municípios de acordo com os dados do IBGE (2018) corresponde à cerca 760.000 ha.

\section{RESULTADOS E DISCUSSÃO}

\section{Distribuição quantitativa e temporal}

Nas cidades cobertas pela pesquisa ocorreram 1.155 autuações ambientais entre os anos de 2015 a 2018, referentes à degradação ambiental, atividades minerárias, poluição, flora, recursos hídricos, pesca embarcada e pesca desembarcada, conforme Tabela 2.

Necessário esclarecer que as informações acerca das autuações contra a fauna não contemplaram os anos de 2015 e 2016, contudo, quanto aos anos seguintes os dados informam que em 2017 ocorreram 63 autuações e, em 2018 foram lavrados 107 autos de infração. Assim, as autuações contra a fauna não constam nas tabelas e gráficos específicos sobre autuações, entretanto outras informações sobre a fauna 
são objetos de análise particularizada.

Tabela 2: Número de autuações ambientais de 2015 a 2018.

\begin{tabular}{l|l|l|l|l|l|l|l|l}
\hline Anos & Deg. & Min. & Pol. & Flora & R.Hid & P.Des. & P.Emb & Total \\
\hline 2015 & 1 & 6 & 24 & 176 & 37 & 26 & 7 & 277 \\
2016 & 14 & 3 & 8 & 180 & 33 & 32 & 7 & 277 \\
2017 & 16 & 5 & 9 & 197 & 33 & 43 & 6 & 309 \\
2018 & 1 & 0 & 20 & 187 & 30 & 47 & 7 & 292 \\
Soma & 32 & 14 & 61 & 740 & 133 & 148 & 27 & 1155 \\
\hline
\end{tabular}

Fonte: Elaborado pelo autor com base nos dados fornecidos pela 2o Pelotão da 6a Companhia de Polícia Militar de Meio Ambiente do Estado de Minas Gerais. Os dados tratam dos números de autuações ambientais relacionadas à Degradação Ambiental, Mineração, Poluição, Flora, Recursos Hídricos, Pesca Embarcada e Pesca Desembarcada.

A Tabela 2 mostra que não houve muita variação quanto ao número total anual de autuações ambientais entre os anos pesquisados. Na Figura 1 fica nítida a diferença entre as autuações que envolvem a flora e as demais autuações, revelando disparidade, sendo necessário estudar as causas desse elevado número de infrações contra a flora e formas de diminuí-lo.

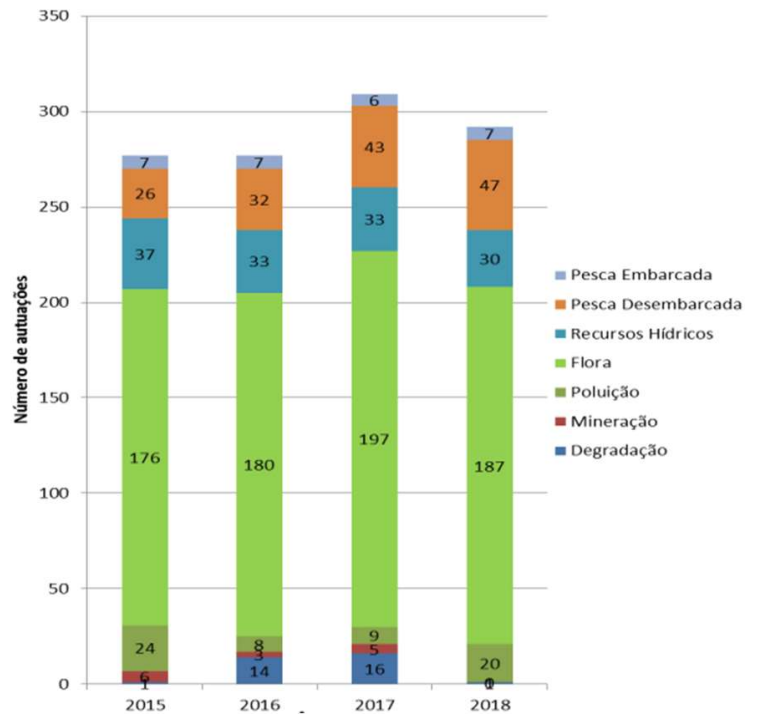

Figura 1: Número de autuações ambientais de 2015 a 2018. Fonte: Polícia Militar do Estado de Minas Gerais.

Diante dos dados observados nota-se que na área de estudo as infrações cometidas contra a flora preponderaram, revelando-se como a classe de autuações mais incidente, seguindo o resultado dos estudos apresentados no referencial teórico (PERES et al., 2016; BAZZANELLA et al., 2017; VIANA et al.; CAMPOS, 2019).

A figura 2 mostra que o ano de 2015 foi o que apresentou o maior número de ocorrência quanto à classe Mineração e isso se deve à realização de uma operação especial, em que as atividades minerárias foram fiscalizadas no município de São Thomé das Letras, onde a extração de quartzito se dá muitas vezes irregularmente, contando com inúmeros mineradores clandestinos. No ano de 2018 não foi realizada nenhuma operação específica sobre as atividades minerárias, como também não foram registradas denúncias, resultando em uma brusca queda das ocorrências de autuações ambientais referentes a essa classe. 


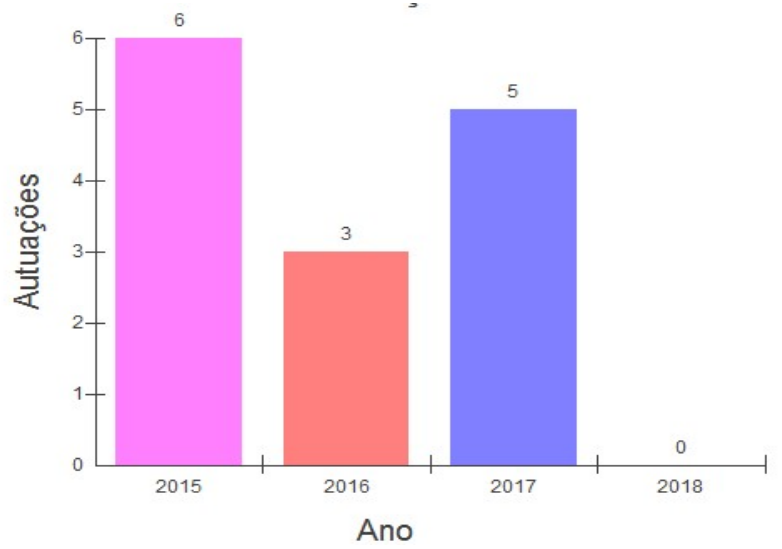

Figura 2: Número de autuações ambientais da classe de mineração de 2015 a 2018.

Fonte: Polícia Militar do Estado de Minas Gerais.

Ao contrário do que ocorreu no Estado da Paraíba onde, segundo Tavares (2016), a falta de licenciamento ou descumprimento de condicionantes ocorreu em maior número e no Estado do Ceará em que as infrações mais comuns são aquelas relativas à poluição e ao descumprimento de licenciamento ambiental (ARAGÃO, 2016), no presente estudo constatou-se que, mesmo somando-se em cada ano todas as autuações das classes correspondentes à Mineração (Figura 2), Degradação (Figura 3) e Poluição (Figura 4), que se referem às infrações relacionadas ao licenciamento e cumprimento de suas condicionantes, não superaram a quantidade de autuações contra a flora. Aliás, as autuações relacionadas à flora em todos os anos representaram mais de $60 \%$ do total de todas as ocorrências.

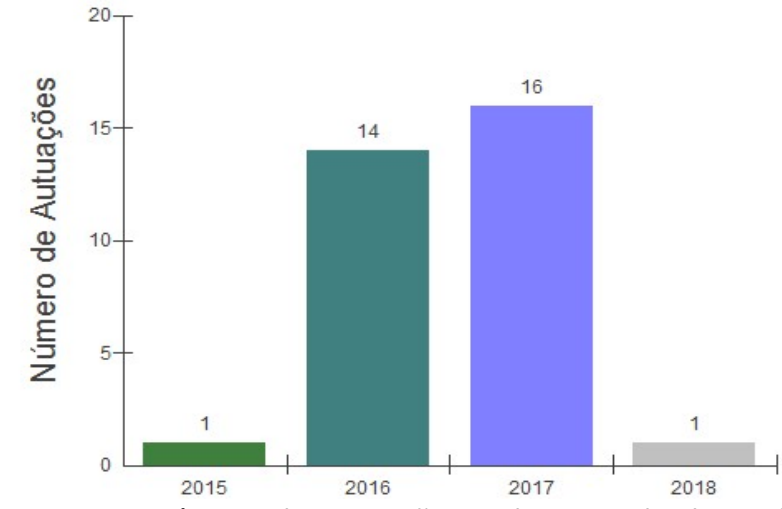

Figura 3 - Número de autuações ambientais da classe de degradação de 2015 a 2018. Fonte: Polícia Militar do Estado de Minas Gerais. $\square 2015 \quad 2016 \quad \square 2017 \quad \square 2018$

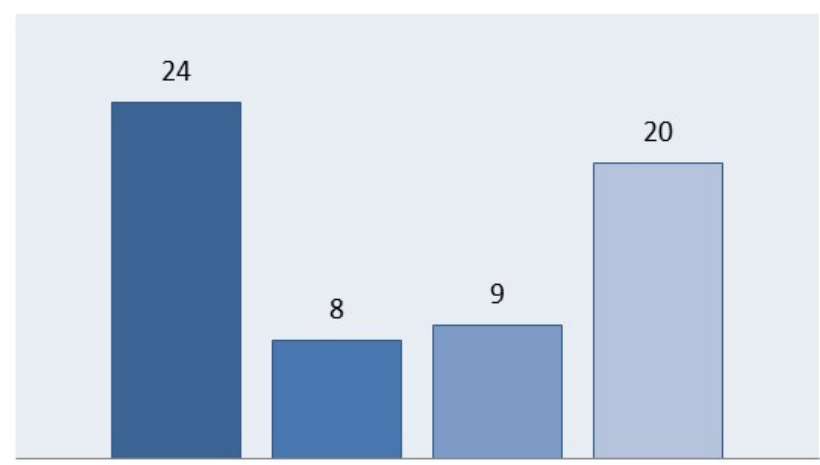

Figura 4: Número de autuações ambientais da classe de poluição de 2015 a 2018.

Fonte: Polícia Militar do Estado de Minas Gerais.

Outra questão relevante se refere aos valores aplicados em multa, sendo que de acordo com os dados fornecidos pela corporação, em 2015 o valor correspondeu a $\mathrm{R} \$ 501.299,40$, aumentando para $\mathrm{R} \$ 602.030,17$ em 2016, R\$1.417.611,85 em 2017 e, em 2018 atingiu o importe de $\mathrm{R} \$$ 2.116.543,69, resultando na Média Aritmética de $\mathrm{R} \$ 1.159 .370,80$ e Coeficiente de Variação de 65.43\% (figura 5).

Cabe esclarecer que em Minas Gerais as multas são aplicadas em UFEMG (Unidade Fiscal do Estado de Minas Gerais) que é corrigida ano a ano. Em 2015 cada UFEMG correspondia ao valor de R\$2,7229 (MINAS GERAIS, 2014), assim, o valor aplicado em multas correspondeu a 184.105 UFEMGs. Em 2016, a UFEMG valia $\mathrm{R} \$ 3,0109$ (MINAS GERAIS, 2015), portanto o valor aplicado em multas correspondeu a 199.950 UFEMGs. No ano de 2017 com a UFEMG valendo R\$3,2514 (MINAS GERAIS, 2016), foi aplicado o 
valor equivalente a 436.000 UFEMGs. Em 2018 a UFEMG teve valor correspondente a $\mathrm{R} \$ 3,2514$ (MINAS GERAIS, 2017), assim, foi aplicado o correspondente a 650.964 UFEMGs. Portanto, foi aplicado o equivalente a 1.471,019 UFEMGs em multas e, considerando que a UFEMG em 2020 vale R\$ 3,7116 (MINAS GERAIS, 2019), o valor atual das multas aplicadas de 2015 a 2018 corresponde a $\mathrm{R} \$ 5.459 .834,12$.

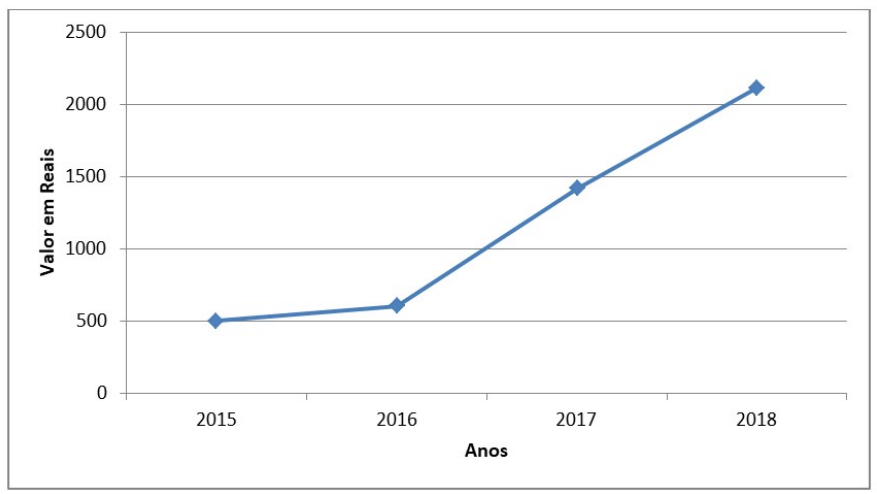

Figura 5: Valor em Reais (mil/milhões) do total das multas aplicadas de 2015/2018.

Fonte: Polícia Militar do Estado de Minas Gerais

Portanto, ocorreu uma progressão linear quanto ao valor total anual das multas, e isto possivelmente se deu em razão da mudança na legislação aplicável, ocorrida no 10 trimestre de 2018. Entretanto, não se pode afirmar como sendo este o motivo do aumento do valor total das multas aplicadas na região com plena certeza, tendo em vista que do ano de 2016 para 2017 quando ainda vigorava o Decreto Estadual no 44.844/2008 a soma dos valores mais que dobrou. Desse modo, esta questão merece outra pesquisa mais aprofundada para apuração das diferenças e tendência.

Apesar da elevação dos valores aplicados em multas aplicadas pela Polícia Ambiental, muitos infratores não realizam o seu pagamento, sendo certo ainda que quando é lavrado o auto de infração, é concedido o prazo de 20 dias para o suposto infrator apresentar defesa administrativa a ser processada e julgada pela Diretoria de Autos de Infração com relação às autuações lavradas até o ano de 2015 e, pelo Núcleo de Autos de Infrações (NAI) da Superintendência Regional de Meio Ambiente e Desenvolvimento Sustentável do Sul de Minas (Supram-Sul) quanto às autuações lavradas a partir de 2016, da decisão podendo ser apresentado recurso.

Em muitos casos de autuações ambientais são aplicadas apenas multas, já as demais penalidades são aplicadas de forma cumulada com as próprias multas, como a suspensão de atividades, embargo à obra, apreensão de bens. Portanto a penalidade de multa é amplamente aplicada. Quanto à fauna os dados se referem aos animais recolhidos, apreendidos e prisões, como mostra a Figura 6.

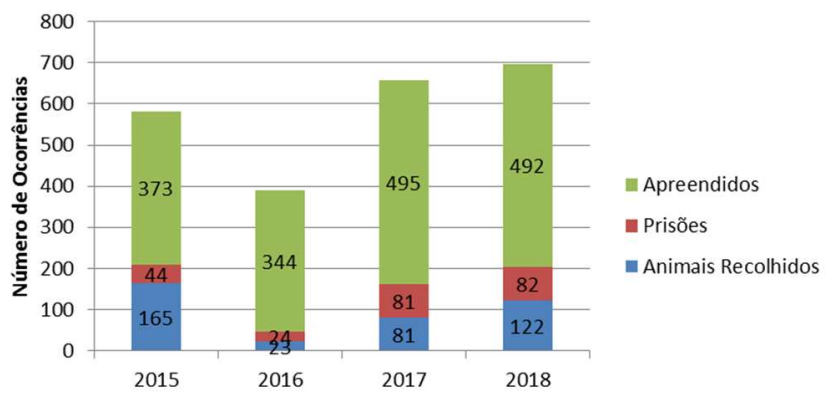

Figura 6: Número de ocorrências relacionadas à fauna de 2015 a 2018.

Fonte: Polícia Militar do Estado de Minas Gerais 
Conforme já ponderado, o número de autuações ocorridas contra a fauna no período de estudo foi fornecido de modo incompleto, ou seja, as planilhas analisadas possuem uma lacuna de informações relativa a esta classe quanto aos anos de 2015 e 2016, sendo que no ano de 2017 ocorreram 63 autuações e, em 2018 foram lavrados 107 autos de infração. Analisando a Figura 6, nota-se a grande quantidade de animais apreendidos anualmente.

O estudo realizado no Canadá por Luscombe et al. (2014) revelou que muito embora os policiais ambientais locais (policiais de conservação) se definam como educadores ambientais públicos, as ações que realizam muitas vezes se assemelham às mesmas ações praticadas pelas outras polícias que lhes acionam, ou seja, suas ações muitas vezes se distanciam das questões ligadas ao meio ambiente devido às demandas da polícia comum. Além disso, eles trabalham sob demanda de denúncias da população concentrando-se nos parques das cidades de Otawa, Calgary, Toronto e Vancouver, isto é, nas maiores cidades canadenses. Essas características diferem bastante das características dos policiais ambientais do presente estudo que, apesar de também trabalharem na maioria das vezes sob a demanda de denúncias, realizam a fiscalização de indústrias, mineradoras, propriedades rurais, parques estaduais, corpos hídricos e a conscientização ambiental através da promoção de palestras em escolas da região. Portanto, a polícia ambiental objeto de estudo abarca uma gama maior de ações com relação às atividades dos policiais de conservação canadenses e também em comparação aos oficiais conservacionistas dos Estados Unidos que exercem atividades mais direcionadas à pesca e proteção de animais em risco de extinção, além das atividades desempenhadas pela polícia comum, mais recentemente.

É possível entender que há correlação entre as atividades desenvolvidas pelas policiais ambientais em diferentes regiões e países, sendo que a aplicação da educação ambiental é um instrumento de política ambiental que notavelmente vem se destacando, assumindo um caráter estratégico. Nesse sentido, são interessantes as ponderações levantadas na pesquisa bibliográfica com relação ao argumento de que falta educação ambiental da população (TAVARES, 2016). O alto número de infrações contra a flora na região de estudo e notadamente em várias partes do Brasil pode ter relação direta com o custo da desconformidade ambiental que é internalizado pelos empreendedores, ou seja, muitos preferem contabilizar o risco de sofrer sanções, compensando em economia o investimento que teriam com a regularização ambiental (ROUSSEAU, 2009; PERES et al., ARAGÃO, 2016; BARRET et al, 2018).

Em um país rico em vegetação nativa, ou seja, em um território que ainda possui vasta cobertura vegetal natural, certamente muitos arriscam desmatar ao arrepio das leis, devastando florestas sem a devida autorização dos órgãos ambientais, acreditando que o custo de se fazer o que a lei manda pode ser muito alto, ao passo que em muitos casos a fiscalização nem chega a ser realizada e mesmo que ocorra a autuação ainda vigora a cultura da impunidade. Assim, conforme Beccaria (2002), os infratores cometem a infração quando os benefícios do ato superam os riscos.

Nas pesquisas realizadas por Rousseau (2009) além de Ferreira et al. (2015), observou-se que os consumidores vêm cobrando dos agricultores e empreendedores ações positivas relacionadas às questões ambientais. Este comportamento pode diminuir as infrações contra a flora levando-se em conta os locais 
dos estudos, Amazônia e Estados Unidos, podendo se tornar uma tendência. Restou evidenciada a importância de se promover ações preventivas através da Educação Ambiental, a exemplo do que ocorre no Chile, onde segundo Delgado (2016) a conscientização, a reparação do dano e a compensação ambiental fazem frente à aplicação da penalidade de multa ou outras punições. De acordo com o autor, a administração pública chilena investiu em educação e conscientização ambiental visando prevenir a ocorrência de infrações e danos ambientais, contudo, caso ocorram, busca-se a compensação ou reparação do dano e não a arrecadação através da aplicação de multas ou a punição por meio de outras penalidades.

De todo o exposto, cumpre ponderar que a polícia de meio ambiente da localidade do estudo possui uma agenda de ações focadas na área ambiental bem mais abrangente do que a agenda de atividades da polícia de meio ambiente de outros países pesquisados, como os Estados Unidos e Canadá.

Através da pesquisa observou-se que no Brasil a polícia de meio ambiente fiscaliza e autua por delegação de poderes em razão da celebração de convênio com órgãos e entidades da União, dos Estados, do Distrito Federal e dos Municípios responsáveis pela proteção, melhoria e recuperação da qualidade ambiental, que formam o Sistema Nacional de Meio Ambiente - SISNAMA. Observou-se que a polícia ambiental está presente em muitos estados brasileiros e em outros países, contudo, através dessa pesquisa não foi possível afirmar que a polícia de meio ambiente está presente em todas as unidades da federação brasileira. Ainda, em determinadas localidades suas atividades são mais generalistas enquanto na região de estudo suas ações são bem concentradas nas questões ambientais, porém não foi possível afirmar que não exerçam atividades não pertencentes a essa específica área.

O estudo mostrou que existem diferentes classes de autuações ambientais relacionadas às infrações contra a flora, fauna, degradação, poluição, recursos hídricos e pesca, sendo que as infrações contra a flora representaram a maioria das ocorrências, confirmando o resultado encontrado em quatro outras localidades das seis pesquisadas. Apesar da constatação e confirmação da tendência demonstrada na maioria dos outros estudos é necessário frisar que em todas as pesquisas o nível de consciência da sociedade, interesses e comportamentos se limitam a um espaço de tempo e evidentemente podem mudar, portanto, a classe de autuações contra flora pode vir a deixar de ser a mais preponderante.

A aplicação da penalidade de multa é quase a regra em todas as ocorrências de infrações ambientais tendo em vista que as demais penalidades são aplicadas de forma cumulada com a própria multa, como a suspensão de atividades, embargo às obras, apreensão de bens. Ademais, não foi possível afirmar que a penalidade de multa no período de estudo foi a mais incidente, pois, esta penalidade é expressa em valores, diferentemente das outras penalidades ligadas diretamente a cada tipo de atividade fiscalizada, sendo ainda que muitas infrações leves são passíveis apenas de advertência.

\section{CONCLUSÕES}

A maioria das questões levantadas nesse trabalho foi respondida, sendo observado que a polícia de meio ambiente realiza a fiscalização e autuação ambiental, assim como os órgãos responsáveis pela manutenção da qualidade ambiental, estando presente em muitas outras localidades além da região de 
estudo onde concentra mais suas atividades nessa área específica. Constatou-se que existem diferentes classes de autuações ambientais, sendo que no período de estudo e localidade o número de autuações se manteve estável ocorrendo 277 nos anos de 2015 e 2016, 309 em 2017 e 292 no ano de 2018, sendo que em todo o período as infrações contra a flora foram as mais recorrentes.

O panorama gerado pela análise dos dados trouxe um alerta diante do predomínio das autuações ambientais lavradas em decorrência de infrações contra a flora que representou mais de 60\% (sessenta por cento) das autuações no período do estudo. Assim deve ser identificada a motivação dessa disparidade, restando evidente a necessidade de se planejar e implantar ações efetivas visando diminuir as ocorrências das infrações contra a flora e também das infrações relacionadas à poluição, degradação, mineração e pesca.

Alguns questionamentos não puderam ser respondidos com exatidão através da análise dos dados, não sendo possível afirmar que a polícia ambiental local restringe suas ações às questões ambientais deixando de realizar atividades atinentes ao policiamento não especializado. Contudo, é crível que a polícia ambiental impeça o cometimento de crimes não ambientais.

O estudo mostrou que a penalidade de multa no Estado de Minas Gerais é expressa em número de UFEMG a ser convertido em valores. Já as outras penalidades muitas vezes são cumuladas com a própria multa, tendo relação direta com a atividade desenvolvida e gravidade, como o caso das penalidades restritivas de direito que se referem à suspensão de atividades, embargo de obras, apreensão de bens, além da penalidade de advertência. Dessa forma torna-se tarefa complexa apontar qual a penalidade mais aplicada em determinada localidade e certo período. Um dos objetivos específicos do estudo foi verificar se houve aumento ou diminuição dos valores da soma total das multas aplicadas na localidade sendo resolvida essa questão a partir da confirmação de aumento, no entanto, não foi possível apontar a razão desse aumento.

A metodologia adotada nessa pesquisa mostrou-se adequada, pois através da pesquisa bibliográfica foi possível identificar classes variadas de autuações ambientais, verificar a tendência de infrações contra a flora confirmando esse predomínio na região de estudo, além de vislumbrar importantes abordagens sobre a aplicação da penalidade de multa e a atuação da polícia ambiental em diferentes locais. Assim, o estudo ampliou a compreensão acerca da importância da fiscalização e autuação ambiental, apontado questões que poderão ser objetos de outros estudos.

Diante dos resultados, surgem novos desafios, sendo o primeiro identificar o principal motivo da predominância da classe de autuações ambientais relativas às infrações contra a flora, analisar a real situação da polícia ambiental da região e de outras localidades e, o terceiro, aprofundar a discussão acerca da aplicação das penalidades aplicadas em decorrência do cometimento de infrações ambientais.

Como esse trabalho demandou a recuperação de outras pesquisas para a análise de conteúdo dos dados disponibilizados pela polícia ambiental e não foram encontradas muitas pesquisas sobre o tema, devem ser realizados outros estudos com o mesmo viés em outras regiões. A partir de pesquisas semelhantes, comparando-se os dados coletados, discussões e resultados, será possível identificar quais 
são as causas motivadoras das infrações ambientais e quais são os melhores instrumentos de gestão como a fiscalização, o incentivo à regularização e a educação ambiental.

\section{REFERÊNCIAS}

ARAGÃO, T. B.; LIMA, P. V. P. S.; MARQUES, E. R. F.. Auto de Infração Ambiental como Instrumento de Gestão Territorial: Fatores Intervenientes. Rev. Equador, v.5, n.4, p.23-42,2016.

BARRET, K. L.; LYNCH, M. J.; LONG, M. A.; STRETESKY, P. B.. Monetary Penalties and Noncompliance with Environmental Laws: a Mediation Analysis. American Journal of Criminal Justice, n.43, p.530-550, 2018. DOI: https://doi.org/10.1007/s12103-017-9428-0

BARROS, D. A.; BORGES, L. A. C.; NASCIMENTO, G. O.; PEREIRA, J. A. A.; REZENDE, J. L. P.; SILVA, R. A.. Breve análise dos instrumentos da política de gestão ambiental brasileira. Rev. Política \& Sociedade, v.11, n. 22, p.55-180, 2012. DOI: https://doi.org/10.5007/2175-7984.2012v11n22p155

BAZZANELLA, S. L.; BORGUEZAN, D.; MAYER, F. H.. As infrações administrativas ambientais na área de abrangência da sede da 6으 Companhia de Polícia Militar Ambiental - uma realidade regional (Estado de Santa Catarina). Rev. Jurídica de Investigación e Innovación Educativa, n.15, 2017.

BECCARIA, C.. Dos delitos e das Penas. São Paulo: CID, 2002

BRASIL. Constituição da República Federativa do Brasil. Brasília: DOU, 1988.

BRASIL. Lei n. 6.938/1981. Dispõe sobre a Política Nacional do Meio Ambiente, seus fins e mecanismos de formulação e aplicação e dá outras providências. Brasília: DOU, 1981.

BRASIL, Lei 9.433/1997. Dispõe sobre a Política Nacional de Recursos Hídricos. Brasília: DOU, 1997.

BRASIL, Decreto no 6.514/2008. Dispõe sobre as infrações e sanções administrativas ao meio ambiente e estabelece o processo administrativo federal para apuração destas infrações. Brasília: DOU, 2008.

CAMPOS, F. C.. Análise das ocorrências dos crimes ambientais registrados na região metropolitana do Vale do Aço - Minas Gerais. Dissertação (Mestrado em Ciências Ambientais) - Universidade de Cuiabá, Cuiabá, 2019.

CARSON, R.. Primavera Silenciosa. 2 ed. São Paulo: Edições Melhoramentos, 1969.

COSTA, E. P.. Poder de polícia ambiental e a administração pública. Rev. Brasileira de Direito Constitucional, n.16, p.1324, 2010.

FALCONE, D.. America's conservation police: Agencies in transition. Policing: An International Journal of Police Strategies \& Management, v.27, n.1, p.56-66, 2004. DOI: https://doi.org/10.1108/13639510410519912

FERREIRA, M. B. M.; SALLES, A. O. T.. Política Ambiental Brasileira: Análise Histórico -Institucionalista da Principais Abordagens Estratégicas. Rev. de Economia -UFPR, v.43, n.2, 2016. DOI: http://dx.doi.org/10.5380/re.v42i2.54001

FERREIRA, M. D. P.; COELHO, A. B.. Desmatamento Recente nos Estados da Amazônia Legal: uma análise da contribuição dos preços agrícolas e das políticas governamentais. Rev. Econ. Sociol. Rural, v.53, n.1, p.91-108. DOI: https://doi.org/10.1590/1234-56781806-9479005301005

HARDIN, G.. The Tragedy of the Commons. Rev. Science, v.162, n.3859, p.1243-1248, 1968.

IBGE. Instituto Brasileiro de Geografia e Estatística. Biomas e sistema costeiro-marinho do Brasil: compatível com a escala 1:250 000. Rio de Janeiro: IBGE, 2019.

LANHAM, C. M.. Exploring the Responsibilities of Wildlife Law Enforcement Officers: An Examination of Citations Issued by Kentucky Conservation Officers. Richmond: Eastern Kentucky University, 2014.

LEAL, P. C. S.; PIETRAFESA, J. P.. Poder de Polícia no Combate às condutas e atividades lesivas ao meio ambiente. Rev. Fragmentos de Cultura, v.18, n.11/12, p.883-893, 2008. DOI: http://dx.doi.org/10.18224/frag.v18i6.751

LUSCOMBE, A.; WALBY, K.. Occupy Ottawa, Conservation Officers, and Policing Networks in Canada's Capital City. Canadian Journal of Criminology and Criminal Justice, v.56, n.3, p.295-322, 2014. DOI: http://dx.doi.org/10.3138/CJCCJ.2014.E34

MAY, P. H.; LUSTOSA, M. C. J.; VINHA, V.; CÁPENA, E. M.; YOUNG, C. E. F.. Política Ambiental. In: MAY, P. H.; LUSTOSA, M. C. J.; VINHA, V.. Economia do Meio Ambiente: teoria e prática 2003, Rio de Janeiro: Elsevier, 2003, p.135-153.

MEADOWS, D. H.. The Limits to Growth: a Report for the Club of Rome's Project on the Predicament of Mankind. New York: Universe Books, 1972.

MINAS GERAIS. Lei $\mathbf{n}=\mathbf{7 . 7 7 2}$ de $\mathbf{1 9 8 0}$. Dispõe sobre a proteção, conservação e melhoria do meio ambiente. Belo Horizonte: DOE, 1980.

MINAS GERAIS. Lei no 13.199 de 1999. Dispõe sobre a Política Estadual de Recursos Hídricos e dá outras providências. Belo Horizonte, DOE, 1999.

MINAS GERAIS. Lei no $\mathbf{1 4 . 1 8 1}$ de 2002. Dispõe sobre a política de proteção à fauna e à flora aquáticas e de desenvolvimento da pesca e da aqüicultura no Estado e dá outras providências. Belo Horizonte: DOE, 2002.

MINAS GERAIS. Decreto Estadual no 44844 de 2008. Dispõe sobre infrações ambientais, autuações, processo administrativo e da outras previsões. Belo Horizonte: DOE, 2008.

MINAS GERAIS. Lei no $\mathbf{2 0 . 9 2 2}$ de 2013. Dispõe sobre as políticas florestal e de proteção à biodiversidade no Estado. Belo Horizonte: DOE, 2013.

MINAS GERAIS. Resolução no $\mathbf{4 . 7 2 3}$ de 2014. Divulga o valor da Unidade Fiscal do Estado de Minas Gerais (UFEMG) para o exercício de 2015. Belo Horizonte: DOE, 2014. 
MINAS GERAIS. Resolução no 4.841 de 2015. Divulga o valor da Unidade Fiscal do Estado de Minas Gerais (UFEMG) para o exercício de 2016. Belo Horizonte: DOE, 2015.

MINAS GERAIS. Resolução no 4.952 de 2016. Divulga o valor da Unidade Fiscal do Estado de Minas Gerais (UFEMG) para o exercício de 2017. Belo Horizonte: DOE, 2016.

MINAS GERAIS. Resolução no $\mathbf{5 . 0 7 3}$ de 2017. Divulga o valor da Unidade Fiscal do Estado de Minas Gerais (UFEMG) para o exercício de 2018. Belo Horizonte: DOE, 2017.

MINAS GERAIS. Decreto Estadual no 47383 de 2018. Regula a Gestão Ambiental, versando sobre infrações ambientais, fiscalização, autuações, penalidades, processos administrativos, entre outras providências. Belo Horizonte: DOE, 2018.

MINAS GERAIS. Resolução no $\mathbf{5 . 3 2 0}$ de 2019. Divulga o valor da Unidade Fiscal do Estado de Minas Gerais (UFEMG) para o exercício de 2020. Belo Horizonte: DOE, 2019.

MITCHAM, C.. The concept of sustainable development: its origins and ambivalence. Technology in Society, v.17, n.3, p. 311-326, 1995. DOI: http://dx.doi.org/10.1016/0160791x(95)00008-f

IBM. Portaria no 14, de 29 de junho de 2017. Regimento Interno do Instituto Brasileiro do Meio Ambiente e dos Recursos Naturais Renováveis - IBAMA. Brasília: DOU, 2017.

NAVES, R. P.; VAN DEN BERG, E.. Caracterização de uma floresta estacional semidecidual em Varginha, MG. CERNE, v. 18, n.3, p.361-370, 2012.

OLSEN, W.. Coleta de dados. Debates e métodos fundamentais em pesquisa social. Porto Alegre: Penso, 2015.

PERCIVAL, R. V.; ZHAO, H.. The role of civil society in environmental governance in the United States and China. Duke Environmental Law \& Policy Forum, v.24, p.141-182, 2013.
PERES, R. P.; UHR, J. G. Z.; UHR, D. A. P.. Infrações contra a Flora e Multas Aplicadas: Análise Espacial para o Brasil. Rev. Iberoamericana de Economia Ecológica, v.26, p.89-127, 2016.

ROUSSEAU, S.. Empirical analysis of sanctions for environmental offenses. International Review of Environmental and Resource Economics, v.3, n.3, p.161194, 2009. DOI: http://dx.doi.org/10.1561/101.00000024

MOTTA, R. S.; REIS, J. E.. O financiamento do processo de desenvolvimento. Revista de Administração Pública, v.26, n.1, p.163-187, 1992.

DELGADO, P. S.. Sanciones administrativas como medidas de cumplimiento del Derecho: un enfoque funcional y responsivo aplicado al régimen sancionatorio ambiental. Rev. lus et Praxis, v.22, n.2, p.189-226. 2016. DOI: http://dx.doi.org/10.4067/S0718-00122016000200007

TAVARES, R. A.. Distribuição dos autos de infrações ambientais lavrados pela fiscalização estadual da Paraíba no ano de 2014. Monografia (Graduação em Engenharia Sanitária e Ambiental)- Universidade Estadual da Paraíba, Campina Grande, 2016.

TRENNEPOHL, T.. Direito ambiental: obra recomendada para concursos públicos. 3 ed. Salvador: Podium, 2008.

VARELA, C. A.. Instrumentos de Políticas Ambientais, Casos de aplicação e seus impactos. EAESP/FGV/NPP, São Paulo, 2001.

VIANNA, L. M.; LEMOS, O. L.. Infrações ambientais na região do parque nacional da Chapada Diamantina-BA. Rev. Núcleo do Conhecimento, v.9, p.5-15, 2019.

WEDY, G.. Litígios Climáticos de acordo com o Direito Brasileiro, Norte-Americano e Alemão. Salvador: JusPodivm, 2019.

A CBPC - Companhia Brasileira de Produção Científica (CNPJ: 11.221.422/0001-03) detém os direitos materiais desta publicação. Os direitos referem-se à publicação do trabalho em qualquer parte do mundo, incluindo os direitos às renovações, expansões e disseminações da contribuição, bem como outros direitos subsidiários. Todos os trabalhos publicados eletronicamente poderão posteriormente ser publicados em coletâneas impressas sob coordenação da Sustenere Publishing, da Companhia Brasileira de Produção Científica e seus parceiros autorizados. Os (as) autores (as) preservam os direitos autorais, mas não têm permissão para a publicação da contribuição em outro meio, impresso ou digital, em português ou em tradução. 